\title{
Análise do Perfil e do Papel do Analista de Negócios no Contexto Nacional
}

\section{Alternative Title: Analysis of Profile and Role from Business Analysts in National Context}

\author{
Viviane Cortese Zadra \\ Universidade do Vale do Rio dos Sinos \\ São Leopoldo - RS - Brasil \\ vivianez@hotmail.com
}

\author{
Josiane Brietzke Porto \\ Universidade do Vale do Rio dos Sinos \\ São Leopoldo - RS - Brasil \\ josiane_brietzke@hotmail.com
}

\begin{abstract}
RESUMO
$\mathrm{Na}$ Gestão de Processos de Negócio torna-se importante compreender o perfil e o papel do Analista de Negócios, pois esse profissional ajuda uma organização a identificar riscos e oportunidades, evitar custos e perceber benefícios no negócio e em seus processos. Mas, quais são as competências requeridas para atuação como Analista de Negócios e quais as responsabilidades desse papel, numa organização? Este trabalho contribui para o debate nesse tema, identificando e analisando competências requeridas, além das principais responsabilidades desse papel, através de uma survey realizada com analistas de negócio, no contexto nacional. A partir da percepção desses profissionais obteve-se um conjunto das principais competências e responsabilidades para atuação como Analista de Negócios, bem como um mapeamento do nível de presença dessas competências e responsabilidades, no cenário atual.
\end{abstract}

\section{Palavras-Chave}

Analista de Negócios. Competências. Perfil. Papel.

\begin{abstract}
In Business Process Management understanding the profile and the role of the Business Analyst is important, because that professional helps an organization to identify risks and opportunities, avoids costs and realizes benefits in the business and its processes. But what are the skills required to work as a Business Analyst and the responsibilities of that role in an organization? This paper contributes to the debate on this issue, identifying and analyzing skills required, the key responsibilities of this role, through a survey carried out with Business Analysts, in the national context. From the perception of these professionals we obtained a set of the main competencies and responsibilities to act as Business Analyst and a mapping of the presence level of these skills and responsibilities in the current scenario.
\end{abstract}

\section{Categories and Subject Descriptors}

K.6.1 [Management of Computing and Information Systems]: Project and People Management - staffing, training, systems analysis and design.

Permission to make digital or hard copies of all or part of this work for personal or classroom use is granted without fee provided that copies are not made or distributed for profit or commercial advantage and that copies bear this notice and the full citation on the first page. To copy otherwise, or republish, to post on servers or to redistribute to lists, requires prior specific permission and/or a fee.

SBSI 2015, May 26-29, 2015, Goiânia, Goiás, Brazil.

Copyright SBC 2015.
General Terms

Management. Human Factors. Performance.

\section{Keywords}

Business Analyst. Skills. Profile. Role.

\section{INTRODUÇÃO}

Na década de 90 surgiu o Analista de Negócios, o intermediador entre o pessoal de negócios e o pessoal técnico, com uma visão mais ampla, voltada para os negócios [5]. Além de possuir conhecimento técnico sobre Tecnologia da Informação (TI), esse profissional consegue entender e interagir com os especialistas de TI. Seu entendimento do negócio e de seus processos, do relacionamento da empresa com seus clientes e, por conseguinte, das necessidades técnicas da empresa permite repassar informações de um lado (gerência de negócios) para o outro (gerência técnica), garantindo um real entendimento.

Um pouco antes da década de 90 , a área de negócios era de responsabilidade quase que exclusiva dos gestores de negócio, profissionais sem nenhum conhecimento ou experiência em TI [5]. O Analista de Negócios veio unir o conhecimento e a experiência das áreas de negócio e TI para suprir a necessidade das organizações se adaptarem a um mercado competitivo.

Existem algumas discussões sobre a área de formação e a possibilidade de transformar uma pessoa da área técnica num especialista em negócios e vice-versa [5]. Além disso, profissões como Analista de Negócios e Analista de Requisitos tem sido objeto de pesquisas [8]. Porém, não foi encontrado um estudo empírico anterior na revisão de literatura, que aprofundasse quem é o Analista de Negócio em termos de formação, qual o perfil mais adequado para desempenhar esse papel e, ainda, quais as responsabilidades ou atribuições desse papel, numa organização.

Na prática, a maior parte dos trabalhos em Gestão de Processos de Negócio enfatiza questões técnicas, em detrimento de aspectos não técnicos, como os fatores humanos, sociais e organizacionais, que são críticos para o sucesso de projetos nessa área $[17,18,19]$.

Nessa área, o Guia do Corpo de Conhecimento de Análise de Negócios $\left(\mathrm{BABOK}^{\circledR}\right)$ [9], um framework globalmente reconhecido para a profissão de Analista de Negócios apresenta competências fundamentais, que suportam o desempenho eficaz da análise de negócios. Esse guia foca em processos e técnicas, além dessas competências na área de análise de negócios.

Diante desse contexto, o presente trabalho contribui com uma investigação de natureza quantitativa, método de pesquisa survey, a respeito do papel desempenhado e do perfil encontrado nos profissionais do mercado nacional. Contempla um escopo amplo e concebe um instrumento de pesquisa para mensuração da 
importância e da presença de competências e responsabilidades dos Analistas de Negócios. Esse instrumento tem como base uma revisão da literatura sobre o tema e contribui para levantar a opinião dos profissionais sobre as principais responsabilidades e competências importantes e presentes no desempenho dessa profissão, no contexto nacional.

O objetivo geral desse estudo é analisar o perfil e o papel do Analista de Negócios no cenário nacional, segundo a percepção da importância e da presença dos próprios profissionais atuantes nessa área. Para tanto, além dessa introdução, este artigo está organizado em outras quatro seções. A próxima apresenta a fundamentação teórica e a seção 3 trata da metodologia de pesquisa. Na seção 4 são analisados os resultados e a seção 5 aborda considerações finais, contribuições, limitações e pesquisas futuras.

\section{A ANÁLISE DE NEGÓCIOS E O ANALISTA DE NEGÓCIOS}

A análise de negócios pode ser definida como um conjunto de técnicas e de ferramentas, que potencializam a eficiência do negócio, por meio de aproveitamento de oportunidades e da solução de problemas, que surgem e impedem ou influenciam no cumprimento da missão de uma organização. Serve para entender as necessidades do negócio, ou seja, das pessoas numa determinada organização [4]. Segundo o IIBA [9, p. 4], tem por objetivo "compreender a estrutura, políticas e operações de uma organização e recomendar soluções que permitam que a organização alcance suas metas".

Visa fazer um diagnóstico antes de partir para a solução [6]. Entretanto, é comum a construção de uma solução, a partir de um documento que diz exatamente o que tem que ser construído, sem questionar o que está sendo pedido e nem avaliar se aquilo é realmente necessário. Quando isso acontece, se corre o risco de desatender alguma necessidade ou construir soluções inapropriadas, perdendo-se tempo e dinheiro.

O valor da análise de negócios está na identificação do real problema, na escolha da solução apropriada e na comunicação dessas informações a quem vai construir a solução. Portanto, torna-se importante clarear e compreender o perfil requerido e o papel do profissional atuante nessa área.

\subsection{Perfil do Analista de Negócios}

Os profissionais de TI passaram os últimos anos envolvidos com metodologias sistêmicas, estruturando e reestruturando o hardware das organizações, desenvolvendo aplicativos, atualizando-se em tecnologias de ponta. Nesse período, os empresários demoraram a perceber que a TI poderia ser uma forma imbatível de alavancagem de negócios [5]. A década de 90 caracterizou-se pela busca frenética do mercado pela qualidade, competência e produtividade. A informação adequada dentro da organização passou a representar o fator de diferenciação, na gestão de negócios. Com base nisso, o Analista de Negócios surgiu por uma necessidade do meio empresarial, pois aliou a atividade fim da empresa, com a informação gerada das mais diferentes formas, através de processos informatizados.

O Analista de Negócios é uma transformação de perfil, após quase quatro décadas de acomodação do Analista de Sistemas tradicional [5]. Desde o início da década de 80, o mercado passou a buscar um profissional que pudesse apoiar a empresa em seus negócios, em sua forma de competitividade por meio da TI e que tivesse uma visão ampla, além da área de Informática.
Segundo Saviani [5], o Analista de Negócios é um agente de mudanças ligado ao ramo de negócios da organização, procurando desenvolver soluções e sistemas, que inovem a participação da empresa em seu mercado e que torne o uso da TI como uma ferramenta estratégica do mais alto valor. O Analista de Negócios tem seu maior valor, quando trabalha no descobrimento do real problema para, posteriormente, descobrir possíveis soluções e seus respectivos escopos. Sendo assim, o foco do Analista de Negócios deve estar na solução e não no software ou nas inúmeras possibilidades oferecidas pela TI.

Esse profissional se envolve na análise de alternativas de solução para os problemas encontrados, no contexto organizacional e na formulação de justificativas para a solução identificada, bem como na garantia de entrega da solução, que melhor atende as necessidades do negócio. Posteriormente, também se envolve para avaliar se essa solução continuará agregando valor e atendendo as necessidades do negócio em questão.

$\mathrm{Na}$ prática, percebe-se que a fronteira de atuação desse profissional com o profissional de análise de sistemas é pequena, porém, existem diferenças. Para tanto, é importante compreender os contextos de atuação de cada profissional. O Analista de Negócios atua no contexto do negócio e por isso possui uma visão sistêmica e em profundidade do negócio como um todo em diversos aspectos, tais como pontos fracos, pontos de atenção, pontos fortes, o que gera valor, o que é fator crítico de sucesso, quais são os diferenciais, produtos e serviços, funcionamento dos processos principais e das áreas de apoio do negócio, qual a estrutura, estratégias, missão e visão da organização em questão.

Portanto, esse profissional pode facilitar e fornecer requisitos do negócio para o profissional atuante na análise de sistemas, assim como, para qualquer profissional de outra área da organização, que não esteja associada com TI e/ou Sistemas de Informação (SI). Ocorre que um profissional nesse papel atua como um tradutor e "como um integrador na organização como um todo" [10, p. 11].

O Analista de Negócios é o responsável ou parte interessada nas atividades de análise de negócio. Porém, existem papéis alternativos encontrados na prática, como analista de processos, consultor, dono do produto, especialista de solução e ainda, analista de sistemas ou de requisitos [9]. Nesse caso torna-se necessário diferenciá-lo de ao menos alguns deles como o analista de sistemas, supracitado e que é responsável pela análise do problema, definição dos requisitos funcionais e não funcionais e gerência das mudanças nesses requisitos do software. Já, o analista de processos atua mapeando, modelando e melhorando os processos (primários ou de negócio, suporte e de controle) da organização.

\subsubsection{Formação do Analista de Negócios}

Segundo Saviani [5], para se tornar um profissional polivalente como o Analista de Negócios é preciso que a leitura seja um hábito diário, rotineiro e constante. Uma leitura abrangente, envolvendo aspectos de negócios e do comportamento humano e englobando jornais diários e revistas de negócios. O perfil profissional do Analista de Negócios, portanto, requer conhecimentos organizacionais, políticos, humanos e do negócio.

Para que essa visão seja gradativamente assimilada por esse profissional há a necessidade de uma formação em cada segmento da organização, possibilitando uma vivência do negócio como um todo, além das peculiaridades de cada área. A formação universitária deverá ser considerada como meta básica e o ingresso numa pós-graduação é fortemente recomendado. Para 
complementar essa formação deve ser proporcionada uma intensa atualização bibliográfica e participação em eventos, que ampliem seus conhecimentos de determinada atividade empresarial [5].

Para Neves [4] é importante verificar se o profissional leva jeito ou não para Análise de Negócios. Segundo ele, qualquer formação de uma maneira ou de outra agrega valor ao trabalho de Análise de Negócios. Além disso, o autor sugere cursos complementares na área de análise de negócios, de elicitação de requisitos para a identificação das reais necessidades, de engenharia de requisitos e de modelagem e outros, que ajudem a melhorar a comunicação e a programação neurolinguística, para entendimento do comportamento humano. Também recomenda o domínio do Guia BABOK $^{\circledR}$ [9] e certificações como a Certification of Competency in Business Analysis (CCBA) ou Certified Business Analysis Professional (CBAP), pois podem impulsionar a carreira [4].

Essa formação pode possibilitar que o Analista de Negócios tornese um profissional estrategista, que pensa de forma integrada e colaborativa, lidera a integração entre as unidades organizacionais, a partir de práticas, técnicas, habilidades e fundamentalmente, conhecimento. Pode exercer a função de integrador através de suas competências e adota uma postura proativa, em relação ao entendimento das necessidades do negócio, contribuindo para evidenciar a sua participação na geração de valor. Também pode ser capaz de analisar o negócio através das práticas de observação, entrevistas, ações consultivas, tutorias e liderança, e de entender suficientemente de TI ao ponto de viabilizar a gestão empresarial, em tempo real [4].

\subsubsection{Competências do Analista de Negócio}

A literatura aponta a existência de várias definições para o conceito de competência, que se distinguem na ênfase e nas dimensões semântica (função que a competência tem) e estrutural (componentes da competência), nos âmbitos profissional e educacional [11]. Essa variação ocorre principalmente, quando se discute competência, na perspectiva do indivíduo [12].

A abordagem de competência empregada no $\mathrm{BABOK}^{\circledR}$ [9] e nesse artigo pode ser compreendida por uma intervenção eficaz mediante ações, para solucionar um problema ou lidar com uma situação nova, que mobilizam ao mesmo tempo e de forma interrelacionada um conjunto de elementos compostos por conhecimentos, habilidades e atitudes (CHA), num contexto [13].

Nesse artigo, esse contexto refere-se ao de Análise de Negócios e as competências identificadas como fundamentais são apresentadas no Quadro 1. Segundo Neves [4], nada substitui bom senso, honestidade, capacidade de se comunicar, organização e tantas outras competências, que fazem a diferença na prática desse profissional. Porém, é na prática que se sabe se o profissional tem essas competências desenvolvidas para fazer análise de negócios.

Ocorre que o profissional desta área lida intensamente com o ser humano e gera um trabalho sistêmico no contexto em que atua. Por consequência, isto leva a preocupações e tensões dos envolvidos devido a mudanças. As competências identificadas como requeridas na literatura $[4,5,6,9,10]$, para atuação como Analistas de Negócios são resumidas no Quadro 1.

Segundo Saviani [5], essas competências podem ser classificadas em inatas e adquiridas. Para esse autor, as inatas são aquelas herdadas geneticamente, que favorecem ou prejudicam os profissionais de determinadas áreas, tais como criatividade, inteligência emocional, bom senso, liderança e extroversão. Já as adquiridas são as que incorporamos ao nosso comportamento, ao nosso aprendizado no meio em que vivemos, como, por exemplo, conhecimento em tecnologia, empatia e domínio de idiomas.

\section{Quadro 1 - Competências do Analista de Negócios}

\section{Competências}

Gostar de resolver problemas; Gostar de trabalhar com pessoas; Conhecimento da organização; Comunicação; Facilitação e Negociação; Visão apurada; Criatividade, Comunicação, Saber Escrever, Gestão de Conflitos; Pensamento Sistêmico; Proatividade; Empatia; Marketing Pessoal; Bom Senso; Senso de Humor; Dedicação; Pensamento Analítico; Ética; Suportar Pressão; Otimismo; Motivação; Cooperação; Persuasão; Flexibilidade; Autoconfiança; Aceitar Críticas; Influência; Liderança; Pensamento Crítico; Organização Pessoal; Responsabilidade; Gestão do Tempo; Aprendizagem; Trabalho em Equipe; Saber Ensinar; Inteligência Emocional; Extroversão; Conhecimento de Tecnologia; Hipocrisia; Domínio de idioma.

Cada segmento de atividade empresarial tem características próprias e a atualização técnica, constantes leituras, novos comportamentos e sensibilidade para o mercado são providências a serem buscadas por esse perfil [5]. Constata-se que os Analistas de Negócios são negociadores, comunicativos e objetivos. Devem entender o potencial e as limitações da tecnologia, serem conscientes de que a tecnologia não é a única solução para o problema de uma organização, mas podem usá-la para promover mudanças e melhorias contínuas, na organização.

Também existe a necessidade e um desafio de desenvolvimento e de constante construção dessas competências. Behar [13] considera que essa constante construção de competências ocorre devido à necessidade de respostas às demandas de cada contexto em que o indivíduo está inserido. Ressalta-se que o nível de desenvolvimento e de atualização desse conjunto de competências pode variar de um profissional para outro e também de uma organização para outra e, por isso, torna-se importante uma avaliação, que leve em consideração nessa análise o contexto organizacional, como características do modo de estruturação das atividades de análise de negócios, papéis desempenhados, assim como competências organizacionais e as diretrizes estratégicas.

Embora necessário, dificilmente, um profissional possui todas essas competências desenvolvidas de forma plena para a atuação na análise de negócios, até porque não são poucas. Ocorre que um profissional nessa área não nasce pronto, ele evolui e se desenvolve, a partir da prática e isso leva um longo tempo.

\subsection{Papel do Analista de Negócios}

A seção anterior abordou o perfil do Analista de Negócios. Essa trata das responsabilidades em termos de atividades e atribuições desse papel identificadas na literatura $[4,5]$, conforme Quadro 2.

Segundo Neves [4], o mercado prega que a formação em cursos na área de TI é a mais indicada para esse profissional, porém, como se observa no Quadro 1 e no Quadro 2, nem todas as atividades a serem executadas serão suportadas por uma formação nessa área de conhecimento.

Ocorre que os problemas de um negócio, não necessariamente serão resolvidos por uma nova solução relacionada a software ou a qualquer outro recurso tecnológico. $\mathrm{Na}$ verdade, nem sempre a solução pode ser algo ligado aos recursos de TI. Muitas vezes um treinamento ou a reformulação de um processo é a solução.

A partir dessas responsabilidades do Quadro 2 espera-se que Analistas de Negócios sejam capazes de aproximar a TI dos negócios, identificando seus problemas e sugerindo soluções e levando o conhecimento do negócio para os projetos de TI. 
Quadro 2 - Responsabilidades do Analista de Negócios Responsabilidades

Integrar sistemas de informações globais; Vivenciar o negócio da organização; Acompanhar a elaboração de anteprojetos e acompanhar o desenvolvimento até a conclusão; Conhecer o hardware e o software disponíveis no mercado, que possam ser utilizados na organização; Conhecer arquitetura de redes de comunicação da organização e estar a par de novas tecnologias disponíveis; Conhecer a tecnologia de Intercâmbio Eletrônico de Documentos (EDI) e explorar de acordo com o tipo de atividade da organização; Ter condições de ampliar a estrutura de hardware, quanto ao planejamento do crescimento e da troca da estrutura disponível na organização; Pesquisar novos softwares aplicáveis ao ramo de negócio; Ministrar palestras e seminários internos para provocar a disseminação de conhecimentos; Manter contato estreito com a alta direção; Elaborar e/ou revisar o Plano Diretor de Informática; Participar de grupos de controle de qualidade; Participar de entidades ligadas à Informática e ao ramo de negócios da organização; Apresentar trabalhos em eventos afins; Atuar em processos de reengenharia da informação; Identificar alternativas de solução; Criar business cases; Criar planos de ação; Mapear e modelar processos de negócio; Prototipar requisitos e soluções; Modelar e/ou revisar casos de uso; Validar soluções; Rastrear problemas no negócio; Documentar requisitos de negócio.

Na prática, esse papel e suas responsabilidades nem sempre estão claramente definidos e poucas são as organizações com pessoas alocadas exclusivamente nesse trabalho. $\mathrm{Na}$ realidade são observadas organizações sem papéis e responsabilidades bem definidos, com uma carência de pessoal nessa área e, ainda, há prática de compartilhamento de recursos, onde as pessoas precisam dividir suas tarefas diárias com atividades de análise de negócio e de melhoria de processos de negócio [18].

\section{METODOLOGIA DE PESQUISA}

Essa pesquisa caracteriza-se pelo enfoque quantitativo, caráter exploratório e pelo método survey [2]. Com base na revisão teórica, uma versão preliminar do instrumento de pesquisa foi gerada a fim de identificar o nível de presença e de importância de cada competência e responsabilidade no perfil e no papel de Analista de Negócios, respectivamente, a partir da percepção dos profissionais brasileiros, que atuam ou atuaram nessa área.

O instrumento mensurava as variáveis mostradas nos quadros do próximo capítulo, com base numa escala Likert de cinco pontos [2], com opções que variavam de "Ausente" até "Presente", no caso da avaliação da presença e de "Pouco Importante" até "Muito Importante", no caso da avaliação de importância, sendo que para ambos os casos de avaliação existia a opção "Sem Condições de Opinar" (SCO). Também continha um bloco de questões sócio demográficas, para caracterização dos respondentes.

A versão preliminar do instrumento foi evoluída de modo incremental até a versão final, após procedimentos de pré-teste com especialistas e respondentes, para validação das variáveis, aplicabilidade, clareza, legibilidade, layout adequado e solidez teórica das questões [1]. A coleta de dados foi de cortetransversal, via questionário eletrônico no Qualtrics [7], sendo que a amostra não probabilística foi obtida por conveniência, envolvendo analistas de negócio brasileiros, que aceitaram participar da pesquisa por meio de divulgação feita em comunidades da área, Facebook, Linkedin e Twitter, de 12 a 30 de agosto de 2014. Obteve-se um total de 37 questionários iniciados, sendo que todos foram concluídos e atenderam aos critérios de descarte de incompletude ou uso de apenas um ponto da escala.

Após a coleta foram realizadas análises estatísticas nas variáveis sócio demográficas e nas relacionadas à importância e presença do perfil e papel do Analista de Negócios. Também foi calculado o coeficiente Alfa de Cronbach para quantificar e analisar a confiabilidade e consistência interna do instrumento de pesquisa.

\section{ANÁLISE DOS DADOS}

\subsection{Perfil dos Respondentes}

Os respondentes foram caracterizados por critérios de sexo, idade, tempo de experiência como Analista de Negócios, segmento de mercado, nível de formação e área de formação acadêmica. Estas caracterizações não foram usadas para segmentar os resultados, mas são úteis como referência para futuros trabalhos e identificação do profissional atuante no mercado.

Em resumo, a análise descritiva mostra um perfil de maioria do gênero masculino (21), maduros, com idade entre 45 a 54 anos (13), experientes (25), com mais de 5 anos de experiência, cuja maioria trabalha ou já trabalhou em Tecnologia (33), com curso superior completo (35), sendo a maioria nas áreas de Análise e Desenvolvimento de Sistemas (11) e Ciência da Computação (10). Além disso, possuem MBA ou pós-graduação (28) e estiveram subordinados a maior parte do tempo a área de TI (34).

Esse perfil mostra convergência com a literatura, uma vez que a maioria dos respondentes da amostra possuem conhecimento e formação em Tecnologia. Na prática, possivelmente, são técnicos, que se especializaram em negócios, devido à necessidade e demandas de trabalho, servindo como facilitadores e fornecedores de requisitos do negócio para as áreas de TI e/ou SI [10].

Também confirma a formação e o ingresso em pós-graduação, provavelmente, para fins de desenvolvimento de competências requeridas para atuação nessa área e ampliação de conhecimentos em determinada atividade empresarial [5]. Ainda, corrobora com resultados de uma pesquisa conduzida em 2012, onde a maior parte dos Analistas de Negócios estava subordinada à área de TI e possuía curso superior completo e pós-graduação (Lato Sensu ou Stricto Sensu), demonstrando a preocupação desses profissionais com a formação acadêmica e a evolução da carreira [14].

\subsection{Análise do Perfil do Analista de Negócios}

No Quadro 3 são apresentados os resultados em relação à presença das competências, no perfil dos Analistas de Negócios, segundo a percepção dos respondentes da amostra. Duas variáveis se destacaram nesse quadro com as maiores modas, na avaliação de presença, a "C10" e a "C05". No que tange à solução de problemas, esse resultado confirma uma competência fundamental desse papel, segundo a literatura. Trata-se de ter habilidade para resolução de problemas, apreciar análise e investigação de algo desconhecido, busca de causas e de explicações $[4,9]$.

Sobre a extroversão, esse resultado converge com a literatura, uma vez que habilidades para trabalhar e lidar com pessoas consistem em competências essenciais do Analista de Negócio. Isso significa ter habilidades de facilitação e negociação, liderança e influência, trabalho em equipe, paciência, compreender as pessoas de forma geral e sem restrições, saber ouvir e escutar, lidar com conflitos e diferentes necessidades e interesses de cada pessoa na organização, compreendendo o impacto de decisões [9].

No Quadro 3, somente uma variável se mostrou ausente, a "C20", onde dois respondentes afirmaram não possuir essa competência presente, nos seus respectivos perfis. 
Quadro 3 - Presença das competências no perfil

\begin{tabular}{|c|c|c|c|c|c|c|c|c|}
\hline \multicolumn{2}{|r|}{ PERFIL } & \multicolumn{7}{|c|}{ Avaliação de Presença } \\
\hline & & 1 & 2 & 3 & 4 & & Sco & Moda \\
\hline C10 & Gostar de resolver problemas - gostar e sentir prazer em resolver problemas & 0 & 0 & 3 & 12 & 22 & 0 & 5 \\
\hline $\cos$ & $\begin{array}{l}\text { Extroversão - ser uma pessoa de fácil convivência, simpática e receptiva ao } \\
\text { comportamento dos demais }\end{array}$ & 0 & 2 & 8 & 12 & 15 & 0 & 5 \\
\hline $\mathrm{CO3}$ & $\begin{array}{l}\text { Bom senso - saber agir em determinadas situaç̧os, por meio de palavras, atitudes, } \\
\text { postura }\end{array}$ & 0 & 0 & 3 & 19 & 14 & 1 & 4 \\
\hline CO4 & $\begin{array}{l}\text { Liderança - saber conduzir as pessoas, fazendo com que seja respeitado e que } \\
\text { acreditem em seu trabalho }\end{array}$ & 0 & 1 & 3 & 17 & 15 & 1 & 4 \\
\hline C13 & $\begin{array}{l}\text { Saber se comunicar - fazer com que todos os envolvidos consigam entender você e } \\
\text { também um ao outro }\end{array}$ & 0 & 0 & 5 & 17 & 14 & 1 & 4 \\
\hline C17 & Autoconfiança - ter a convicção de ser capaz de fazer ou realizar o seu trabalho & 0 & 1 & 4 & 17 & 15 & 0 & 4 \\
\hline $\mathrm{CO}$ & Empatia - capacidade de nos colocarmos no lugar da pessoa a qual conversamos & 0 & 0 & 6 & 17 & 14 & 0 & 4 \\
\hline $\mathrm{CO1}$ & Ter criatividade - propor soluccões criativas, práticas, racionais e econômicas & 0 & 1 & 5 & 17 & 14 & 0 & 4 \\
\hline $\cos$ & $\begin{array}{l}\text { Saber induzir o usuário a falar - ouvir o máximo possivel do usuário, induzindo } 0 \\
\text { mesmo a falar tudo a respeito do sistema }\end{array}$ & 0 & 0 & 8 & 15 & 13 & 1 & 4 \\
\hline C15 & $\begin{array}{l}\text { Visão apurada - compreender o negócio, as operações e a tecnologia. } \\
\text { Compreender o todo e as partes de um projeto }\end{array}$ & 0 & 2 & 5 & 15 & 14 & 1 & 4 \\
\hline C19 & $\begin{array}{l}\text { Suportar pressão - saber suportar as adversidades que surgirão como atingir as } \\
\text { metas e cumprir os prazos }\end{array}$ & 0 & 0 & 8 & 18 & 11 & 0 & 4 \\
\hline $\operatorname{cog}$ & $\begin{array}{l}\text { Domínio do idioma - ter uma linguagem clara, objetiva e não dar margem a duplas } \\
\text { interpretações }\end{array}$ & 0 & 0 & 8 & 18 & 10 & 1 & 4 \\
\hline C18 & Tomar decisões - saber tomar decisoes com consciencia e determinaçao & 0 & 0 & 7 & 20 & 9 & 1 & 4 \\
\hline $\mathrm{CO} 6$ & $\begin{array}{l}\text { Tecnologia - estar atualizado e sempre atento aos ultimos acontecimentos } \\
\text { relativos à area tecnica em que atua }\end{array}$ & 0 & 1 & 8 & 16 & 12 & 0 & 4 \\
\hline C12 & $\begin{array}{l}\text { Ter conhecimento da organização - entender como a organização funciona, como } \\
\text { faz para gerar lucro e como atinge suas metas }\end{array}$ & 0 & 0 & 11 & 13 & 12 & 1 & 4 \\
\hline C11 & $\begin{array}{l}\text { Gostar de trabalhar com pessoas - ter paciência, saber compreender as pessoas } \\
\text { sem restrições. Saber ouvir e assimilar as palavras ditas }\end{array}$ & 0 & 0 & 10 & 18 & 8 & 1 & 4 \\
\hline $\mathrm{CO} 2$ & $\begin{array}{l}\text { Saber lidar com o emocional - saber administrar suas emoçoes de forma sabia e } \\
\text { inteligente e conhecer seu intimo emocional }\end{array}$ & 0 & 1 & 11 & 16 & 8 & 1 & 4 \\
\hline C14 & $\begin{array}{l}\text { Saber lidar com conflitos - compreender o impacto de suas decisões no dia a dia } \\
\text { das pessoas que trabalham na organização }\end{array}$ & 0 & 1 & 9 & 18 & 6 & 3 & 4 \\
\hline $\mathrm{C}_{20}$ & $\begin{array}{l}\text { Pensamento crítico - precisa ser incentivado para que não se desperdice dinheiro } \\
\text { implementando soluçõos sem um foco definido }\end{array}$ & 2 & 1 & 6 & 16 & 9 & 3 & 4 \\
\hline C16 & $\begin{array}{l}\text { Facilidade para aceitar críticas - saber aceitar a opinião das pessoas de forma sábia } \\
\text { e inteligente }\end{array}$ & 0 & 1 & 12 & 20 & 3 & 1 & 4 \\
\hline
\end{tabular}

O Quadro 4 mostra resultados da importância das competências, no perfil dos Analistas de Negócios, segundo a percepção dos respondentes. Nesse quadro, valores bimodais são encontrados, sendo o menor valor usado para fins de cálculos estatísticos.

Nessa avaliação observa-se maior volume de competências consideradas importantes pelos respondentes, com moda igual ao valor 5 (importância muito forte). Por sua vez, a variável "C04" apresentou valor bimodal, sendo utilizado o menor valor para fins de cálculos estatísticos. As variáveis "C19", "C05" e "C16" apresentaram importância forte, moda igual a 4 .

Diante desses resultados evidencia-se que o conjunto de competências inicialmente identificado na literatura como requerido para atuação como Analista de Negócio é na prática essencialmente importante, na percepção dos respondentes dessa amostra. Em função disso, reconhece-se como necessário o desenvolvimento dessas competências, nesse contexto.

\section{Quadro 4 - Importância das competências no perfil}

\begin{tabular}{|c|c|c|c|c|c|c|c|c|}
\hline & \multirow{2}{*}{ PERFIL } & \multicolumn{7}{|c|}{ Avaliação de Importância } \\
\hline & & 1 & 2 & 3 & 4 & & Sco & Moda \\
\hline C13 & $\begin{array}{l}\text { Saber se comunicar - fazer com que todos os envolvidos consigam entender você e } \\
\text { também um ao outro }\end{array}$ & 0 & 0 & 1 & 10 & 25 & 1 & 5 \\
\hline $\mathrm{CO}$ & $\begin{array}{l}\text { Bom senso - saber agir em determinadas situações, por meio de palavras, atitudes, } \\
\text { postura }\end{array}$ & 0 & 0 & 3 & 7 & 26 & 1 & 5 \\
\hline $\cos$ & $\begin{array}{l}\text { Saber induzir o usuário a falar - ouvir o máximo possível do usuário, induzindo o } \\
\text { mesmo a falar tudo a respeito do sistema }\end{array}$ & 0 & 0 & 2 & 9 & 25 & 1 & 5 \\
\hline $\operatorname{cog}$ & $\begin{array}{l}\text { Domínio do idioma - ter uma linguagem clara, objetiva e não dar margem a duplas } \\
\text { interpretações }\end{array}$ & 0 & 0 & 3 & 9 & 24 & 1 & 5 \\
\hline C15 & $\begin{array}{l}\text { Visão apurada - compreender o negócio, as operações e a tecnologia. } \\
\text { Compreender o todo e as partes de um projeto }\end{array}$ & 0 & 0 & 4 & 9 & 23 & 1 & 5 \\
\hline $\mathrm{CO1}$ & Ter criatividade - propor soluçōes criativas, práticas, racionais e econômicas & 0 & 1 & 0 & 15 & 21 & 0 & 5 \\
\hline C11 & $\begin{array}{l}\text { Gostar de trabalhar com pessoas - ter paciência, saber compreender as pessoas } \\
\text { sem restrições. Saber ouvir e assimilar as palavras ditas }\end{array}$ & 0 & 0 & 4 & 10 & 22 & 1 & 5 \\
\hline $\mathrm{CO}$ & Empatia - capacidade de nos colocarmos no lugar da pessoa a qual conversamos & 0 & 0 & 3 & 13 & 21 & 0 & 5 \\
\hline C12 & $\begin{array}{l}\text { Ter conhecimento da organização - entender como a organização funciona, como } \\
\text { faz para gerar lucro e como atinge suas metas }\end{array}$ & 0 & 0 & 4 & 11 & 21 & 1 & 5 \\
\hline C20 & $\begin{array}{l}\text { Pensamento crítico - precisa ser incentivado para que não se desperdice dinheiro } \\
\text { implementando soluçôes sem um foco definido }\end{array}$ & 0 & 0 & 3 & 13 & 18 & 3 & 5 \\
\hline C14 & $\begin{array}{l}\text { Saber lidar com conflitos - compreender o impacto de suas decisões no dia a dia } \\
\text { das pessoas que trabalham na organização }\end{array}$ & 0 & 0 & 3 & 14 & 18 & 2 & 5 \\
\hline $\mathrm{CO}$ & $\begin{array}{l}\text { Saber lidar com o emocional - saber administrar suas emoçoes de forma sabia e } \\
\text { inteligente e conhecer seu intimo emocional }\end{array}$ & 0 & 1 & 4 & 11 & 20 & 1 & 5 \\
\hline C18 & Tomar decisões - saber tomar decisoes com consciencia e determinaçao & 0 & 1 & 3 & 15 & 17 & 1 & 5 \\
\hline $\mathrm{C17}$ & Autoconfiança - ter a convicção de ser capaz de fazer ou realizar o seu trabalho & 0 & 0 & 6 & 13 & 18 & 0 & 5 \\
\hline 006 & $\begin{array}{l}\text { Tecnologia - estar atualizado e sempre atento aos ultimos acontecimentos } \\
\text { relativos à area tecnica em que atua }\end{array}$ & 0 & 1 & 6 & 13 & 16 & 1 & 5 \\
\hline $\mathrm{C10}$ & Gostar de resolver problemas - gostar e sentir prazer em resolver problemas & 1 & 1 & 4 & 13 & 17 & 1 & 5 \\
\hline COA & $\begin{array}{l}\text { Liderança - saber conduzir as pessoas, fazendo com que seja respeitado e que } \\
\text { acreditem em seu trabalho }\end{array}$ & 0 & 1 & 1 & 17 & 17 & 1 & $4^{*}$ \\
\hline C19 & $\begin{array}{l}\text { Suportar pressão - saber suportar as adversidades que surgirão como atingir as } \\
\text { metas e cumprir os prazos }\end{array}$ & 0 & 2 & 4 & 16 & 15 & 0 & 4 \\
\hline $\mathrm{CO5}$ & $\begin{array}{l}\text { Extroversão - ser uma pessoa de fácil convivência, simpática e receptiva ao } \\
\text { comportamento dos demais }\end{array}$ & 0 & 2 & 6 & 17 & 11 & 1 & 4 \\
\hline C16 & $\begin{array}{l}\text { Facilidade para aceitar críticas - saber aceitar a opinião das pessoas de forma sábia } \\
\text { e inteligente }\end{array}$ & 0 & 0 & 7 & 20 & 8 & 2 & 4 \\
\hline
\end{tabular}

* Foi utilizado o menor valor encontrado (4 e 5)

\subsection{Análise do Papel do Analista de Negócios}

No Quadro 5 são apresentados os resultados em relação à presença das responsabilidades, no papel dos Analistas de Negócios, segundo a percepção dos respondentes da amostra. Nesse quadro, as variáveis "C25" e "C 35 " apresentaram valores bimodais e percebe-se heterogeneidade de valores em relação à moda, mostrando divergência de opiniões dos respondentes, em relação às responsabilidades presentes no papel de Analista de Negócios. Isso pode ser pelo fato dos limites de atuação e atribuições desse papel não estarem ainda claramente definidas e consolidadas na realidade do mercado de trabalho, no país.

Outra explicação pode estar associada ao fato de que cada organização possui um modo particular de organizar e estabelecer as atividades de Análise de Negócio, sendo que isso pode ter influenciado na prática das responsabilidades e atribuições desse papel, na realidade dos respondentes da amostra, divergindo em relação ao conjunto identificado, a partir da literatura.

Por sua vez, esse resultado ajuda a justificar a importância da área de conhecimento de Planejamento e Monitoramento da Análise de Negócio, no Guia BABOK ${ }^{\circledR}$ [9]. Essa área aborda como planejar e monitorar o trabalho e as atividades de análise de negócios a serem feitas. Abrange a identificação das partes interessadas, papéis e responsabilidades, seleção de técnicas a serem adotadas, o processo a ser usado para o gerenciamento de requisitos e como serão avaliados o desempenho e o progresso desse trabalho [9]. 
Quadro 5 - Presença das responsabilidades no papel

\begin{tabular}{|c|c|c|c|c|c|c|c|c|}
\hline \multirow{2}{*}{\multicolumn{2}{|c|}{ PAPEL }} & \multicolumn{7}{|c|}{ Avaliação de Presença } \\
\hline & & \multirow{2}{*}{\begin{tabular}{|l|l|}
1 & \\
0 & \\
\end{tabular}} & \multirow{2}{*}{\multicolumn{2}{|c|}{\begin{tabular}{|l|l|}
2 & 3 \\
3 & 3 \\
\end{tabular}}} & \multirow{2}{*}{\begin{tabular}{l|l}
4 & \\
14 & 1 \\
\end{tabular}} & \multicolumn{3}{|c|}{5 Sco Moda } \\
\hline C34 & Validar soluçôes & & & & & & 0 & 5 \\
\hline C30 & $\begin{array}{l}\text { Atuar em processos de reengenharia da informação - } \\
\text { readequação dos sistemas de informação, objetivando uma } \\
\text { melhoria nos resultados da organizzação }\end{array}$ & 4 & 4 & 6 & 10 & 12 & 1 & 5 \\
\hline & $\begin{array}{l}\text { Criar o business case ou um documento que formalize } \\
\text { recursos, investimentos e o retorno esperado com um }\end{array}$ & & & & & & & \\
\hline C32 & projeto & 3 & 7 & 9 & 6 & 10 & 2 & 5 \\
\hline C27 & Participar de grupos de Controle de Qualidade (CO) & 7 & 7 & 7 & 5 & 9 & 2 & 5 \\
\hline C23 & Acompanhar a elaboração de anteprojetos & 2 & 5 & 9 & 11 & 6 & 4 & 4 \\
\hline $\mathrm{C} 31$ & Identificar alternativas de solução & 0 & 1 & 6 & 18 & 11 & 1 & 4 \\
\hline C35 & Rastrear problemas & 0 & 3 & 8 & 12 & 12 & 2 & $4^{*}$ \\
\hline $\mathrm{C} 22$ & $\begin{array}{l}\text { Vivenciar o negócio da organização se envolvendo em suas } \\
\text { atividades e planos }\end{array}$ & 0 & 4 & 5 & 16 & 11 & 1 & 4 \\
\hline $\mathrm{C21}$ & Integrar sistemas & 0 & 1 & 13 & 15 & 8 & 0 & 4 \\
\hline $\mathrm{C33}$ & Criar planos de ação & 2 & 5 & 11 & 10 & 8 & 1 & 3 \\
\hline 226 & Manter contato estreito com a diretoria da empresa & 2 & 6 & 12 & 6 & 9 & 2 & 3 \\
\hline $\mathrm{C24}$ & Pesquisar novos softwares & 1 & 8 & 13 & 9 & 4 & 2 & 3 \\
\hline C28 & $\begin{array}{l}\text { Participar de entidades ligadas à informática e ramo de } \\
\text { negócios da organização }\end{array}$ & 6 & 8 & 9 & 7 & 6 & 1 & 3 \\
\hline $\mathrm{C29}$ & Apresentar trabalhos em eventos afins & 9 & 9 & 11 & 1 & 4 & 3 & 3 \\
\hline $\mathrm{C} 25$ & Ministrar palestras e seminários internos & 2 & 10 & 10 & 5 & 8 & 2 & $2^{* *}$ \\
\hline C36 & Leitura de jornais diários e revistas de negócios & 2 & 12 & 7 & 9 & & 0 & 2 \\
\hline
\end{tabular}

* Foi utilizado o menor valor encontrado (4 e 5)

**Foi utilizado o menor valor encontrado (2 e 3 )

No Quadro 5, a variável "C36" teve como moda o valor 2, ou seja, fraca presença. Esse valor obtido nos dados da pesquisa diverge de Saviani [5], onde o hábito da leitura deve ser diário, rotineiro e constante para que o Analista de Negócios se torne um profissional polivalente e com conhecimentos organizacionais, políticos e humanos do negócio.

Já as variáveis "C 34 ", “C30", "C32” e "C27” apresentaram maior presença, na experiência dos profissionais da amostra. Quando analisadas juntas, essas variáveis demonstram na realidade desses profissionais, uma preocupação com a qualidade devido à participação do Analista de Negócios em grupos nessa área. Além disso, representam na prática parte de atividades recomendadas por áreas de conhecimento do Guia BABOK ${ }^{\circledR}[9]$, como a Análise Corporativa e a Avaliação e Validação da Solução.

Os resultados obtidos em relação à importância dessas responsabilidades são apresentados, no Quadro 6. A moda nesse quadro não é tão heterogênea quanto os resultados da moda no Quadro 5, que trata da presença.

No Quadro 6, tem-se um resultado que merece destaque positivo, pois as variáveis "C32" e "C30", consideradas fortemente presentes no Quadro 5, também foram avaliadas com alta importância entre as responsabilidades do Analista de Negócios, na percepção dos respondentes da amostra. Além dessas duas, as variáveis "C 31 ", "C22", "C 35 ", "C26" e "C 36 " também foram consideradas com maior importância nas atribuições desse papel.

Destaca-se que a variável "C36", embora pouco presente na experiência dos respondentes, foi considerada com alta importância nas responsabilidades do Analista de Negócios, na opinião desses profissionais, convergindo com um dos hábitos recomendados por Saviani [5].
Quadro 6 - Importância das responsabilidades no papel

\begin{tabular}{|c|c|c|c|c|c|c|c|c|}
\hline & \multirow{2}{*}{ PAPEL } & \multicolumn{7}{|c|}{ Avaliação de Importância } \\
\hline & & 1 & 2 & & 4 & & Sco $\mathrm{N}$ & Moda \\
\hline C31 & Identificar alternativas de solução & 0 & 1 & 3 & 12 & 20 & 1 & 5 \\
\hline $\mathrm{C} 22$ & $\begin{array}{l}\text { Vivenciar o negócio da organização se envolvendo em suas } \\
\text { atividades e planos }\end{array}$ & 0 & 2 & 4 & 9 & 21 & 1 & 5 \\
\hline & $\begin{array}{l}\text { Criar o business case ou um documento que formalize } \\
\text { recursos, investimentos e o retorno esperado com um }\end{array}$ & & & & & & & \\
\hline C35 & Rastrear problemas & 1 & 2 & 5 & 12 & 16 & 1 & 5 \\
\hline $\mathrm{C} 26$ & Manter contato estreito com a diretoria da empresa & 0 & 4 & 11 & 6 & 14 & 2 & 5 \\
\hline C30 & $\begin{array}{l}\text { Atuar em processos de reengenharia da informação - } \\
\text { readequação dos sistemas de informação, objetivando uma } \\
\text { melhoria nos resultados da organizzação }\end{array}$ & 2 & 4 & 5 & 12 & 14 & 0 & 5 \\
\hline C36 & Leitura de jornais diários e revistas de negócios & 2 & 6 & 6 & 11 & 12 & 0 & 5 \\
\hline C34 & Validar soluções & 1 & 6 & 3 & 13 & 13 & 1 & $4^{*}$ \\
\hline $\mathrm{C} 23$ & Acompanhar a elaboração de anteprojetos & 0 & 1 & 8 & 15 & 11 & 2 & 4 \\
\hline C21 & Integrar sistemas & 0 & 1 & 8 & 18 & 10 & 0 & 4 \\
\hline C28 & $\begin{array}{l}\text { Participar de entidades ligadas à informática e ramo de } \\
\text { negócios da organização }\end{array}$ & 2 & 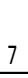 & 10 & 11 & 7 & 0 & 4 \\
\hline C33 & Criar planos de ação & 2 & 5 & 11 & 10 & 8 & 1 & 3 \\
\hline C24 & Pesquisar novos softwares & 0 & 4 & 14 & 10 & 7 & 2 & 3 \\
\hline 225 & Ministrar palestras e seminários internos & 1 & 7 & 13 & 9 & 6 & 1 & 3 \\
\hline C27 & Participar de grupos de Controle de Qualidade (CO) & 1 & 9 & 13 & 7 & 6 & 1 & 3 \\
\hline C29 & Apresentar trabalhos em eventos afins & 6 & 7 & 13 & 6 & 3 & 2 & 3 \\
\hline
\end{tabular}

* Foi utilizado o menor valor encontrado (4 e 5)

Já as responsabilidades "C23", "C24", "C25", "C27" e "C29" foram consideradas com menor importância no papel de Analista de Negócio, conforme a percepção dos respondentes. Isso não significa que não devem ser feitas, mas que podem ter menor ênfase entre as demais ou que são executadas com menor frequência, pois tratam-se de atribuições a serem feitas sob demanda como planos de ação, pesquisas, reuniões e eventos.

\subsection{Análise da Presença e da Importância}

Essa seção mostra um mapeamento da situação atual de presença das variáveis de competências e de responsabilidades, validadas como importantes neste trabalho, no cenário nacional.

A coluna "Gap" da Figura 1 mostra a lacuna entre o que é considerado competência importante pelos respondentes, mas não está presente, ou seja, o que está faltando ser adotado como melhoria no perfil do Analista de Negócios. Trata-se da diferença entre a importância e a presença de cada variável em relação à média calculada e, portanto, essas lacunas podem ser tratadas como oportunidades de melhoria e desafios para $o$ desenvolvimento de competências desses profissionais.

A Figura 1 mostra que os maiores gaps se encontram nas variáveis de competências que lidam com pessoas, sendo elas, em ordem decrescente: "C20", "C14", "C11", "C02", "C09" e "C 08 ". Segundo Saviani [5], o Analista de Negócios lida intensamente com o ser humano, com pessoas que têm sentimentos, ambições e medo, pois mexem no seu trabalho, no seu fator de sobrevivência, sendo papel desse profissional compreender o impacto de suas decisões no dia a dia das pessoas que trabalham na organização. 


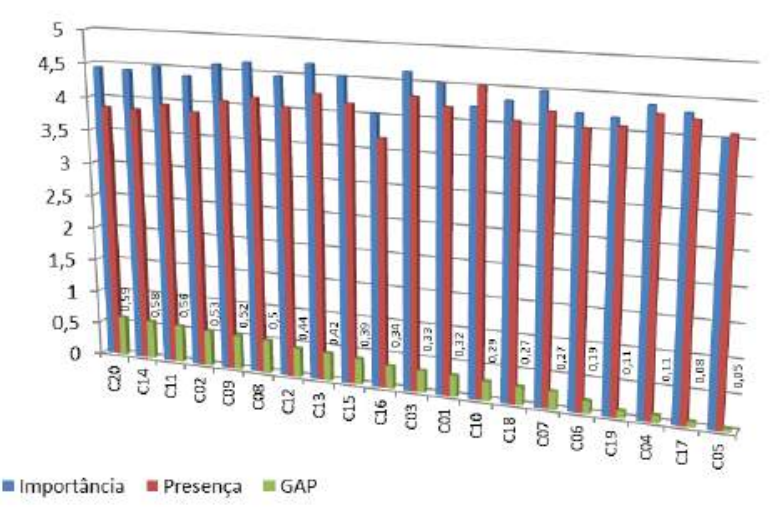

Figura 1 - Importância e presença de competências

Essa lacuna evidenciada nas competências do Analista de Negócio pode ser explicada pelo fato do perfil dos respondentes ser, de um modo geral, representado por profissionais com formação e subordinação na área técnica. Todavia, corroboram para a necessidade de realização de cursos complementares, que ajudem a desenvolver a comunicação e a programação neurolinguística, para fins de entendimento do comportamento humano [4].

Na Figura 2 são comparadas as médias obtidas para as variáveis de responsabilidades importantes no papel do Analista de Negócios, com as médias da presença dessas variáveis. A coluna "Gap" da Figura 2 também mostra a lacuna entre o que é considerado importante pelos respondentes, mas não está presente no papel do Analista de Negócios, podendo ser tratadas como oportunidades de melhoria, na definição dos limites e responsabilidades de atuação desses profissionais. Primeiramente, nessa figura, verificam-se maiores lacunas na situação atual da presença das responsabilidades em relação à importância, quando comparam-se esses valores com os apresentados na Figura 1.

Na Figura 2, as variáveis com maiores lacunas identificadas, em ordem decrescente foram: "C 32 ", "C23", "C26", "C 36 ", "C22" e "C28". Todas as demais variáveis apresentaram lacunas consideráveis de certo modo, sendo o menor valor identificado para a variável "C25". Nesse caso, na avaliação do que faz ou deveria fazer um Analista de Negócios pode ser considerado como algo ainda em amadurecimento, no cenário nacional, embora a importância dessa profissão tenha crescido [15].

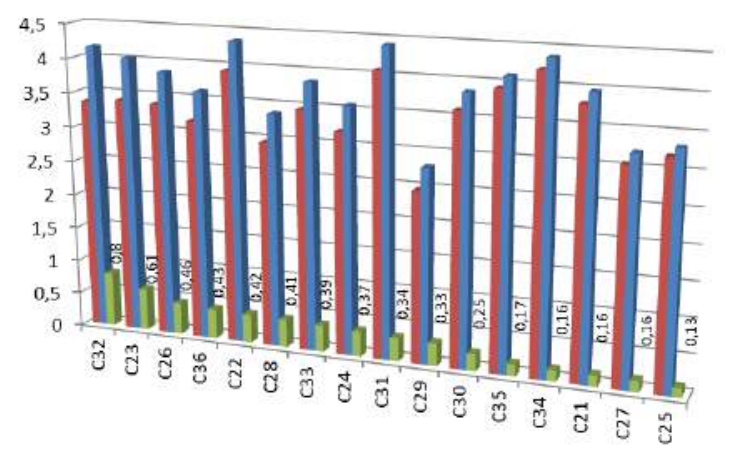

- Importåncia =Presença $=$ GAP

\section{Figura 2 - Importância e presença das responsabilidades}

Uma explicação pode estar associada ao fato desse estudo contribuir para clarear os limites de atuação e as responsabilidades desse papel, a partir de um recorte da literatura, que embasou a construção do instrumento. Porém, na prática e na realidade dos respondentes da amostra podem estar sendo atribuídas nas organizações outras responsabilidades para esse papel.

Outra justificativa pode estar relacionada ao fato de que, recentemente, o Ministério do Trabalho e Emprego (MTE) divulgou o mapeamento da ocupação do Analista de Negócios (1423-30), onde entre outras informações foram definidas suas atividades e a sua classificação na Família Ocupacional 1423, juntamente com as ocupações como Gerente comercial, de comunicação, de marketing e de vendas, relações públicas, analista de pesquisa de mercado e ouvidor [16].

Esse mapeamento da ocupação consiste num avanço significativo nessa área de atuação, pois retrata a realidade dessa profissão no mercado de trabalho brasileiro, bem como pode melhorar nos próximos anos a definição e a situação da presença das responsabilidades desse papel, além do desenvolvimento das competências requeridas para esse perfil, no cenário nacional.

\subsection{Análise de Confiabilidade}

Para a análise de confiabilidade foi calculado o coeficiente Alfa de Cronbach para estimar a confiabilidade do instrumento. Consiste na estatística mais utilizada para se verificar a consistência interna de um conjunto de itens, determinando a confiabilidade de uma medida. Quanto mais alto for o valor do coeficiente, que pode variar de 0 a 1, maior é a consistência interna da medida [3].

Quadro 7 - Consistência interna dos fatores extraídos

\begin{tabular}{|c|l|r|r|}
\cline { 2 - 4 } \multicolumn{1}{c|}{} & Fatores & № de Itens & Alfa de Cronbach \\
\hline \multirow{2}{*}{ Perfil } & Presença & 20 & 0,838 \\
\cline { 2 - 4 } & Importância & 20 & 0,867 \\
\hline \multirow{2}{*}{ Papel } & Presença & 16 & 0,907 \\
\cline { 2 - 4 } & Importância & 16 & 0,863 \\
\hline
\end{tabular}

Nessa pesquisa, os coeficientes obtidos são apresentados no Quadro 7, para cada fator extraído. Esses valores mostram-se satisfatórios devido a sua característica exploratória e estão de acordo com os valores recomendados [2].

\section{CONCLUSÃO}

Este estudo se propôs a analisar o perfil e o papel do Analista de Negócios. Para alcançar esse objetivo, partiu-se para a revisão literatura sobre o surgimento desse profissional, o que ele faz, suas competências e habilidades e a sua importância dentro de uma organização para alavancar os objetivos do negócio. Verificou-se que a análise de negócios define soluções que permitem às organizações atingirem seus objetivos e é com o trabalho do Analista de Negócios que se busca essa solução.

Desde o início da década de 80, o mercado passou a buscar um profissional que utilizando a TI pudesse apoiar a empresa em seus negócios e que tivesse uma visão mais ampla. O Analista de Negócios é a ligação entre as áreas de TI e a de negócios, sendo que o profissional da área de TI é mais técnico e com pouco conhecimento em negócios, já o profissional da Administração conhece pouco de TI e mais de negócios.

Dominar questões técnicas de ambas as formações é primordial para a superação dos desafios e para o desenvolvimento de tarefas, sendo a posição de Analista de Negócios privilegiada por conectar as soluções técnicas aos objetivos de negócio, identificando seus problemas e sugerindo soluções.

A partir dos dados dessa survey evidenciou-se a necessidade de conhecimento em TI e negócio para atuação nesse papel. Também foram identificadas lacunas, no mapeamento da presença das 
competências e responsabilidades, em relação à importância, na percepção dos respondentes. Essas lacunas podem ser tratadas como oportunidades e desafios para os profissionais da área. Esses mapeamentos apresentados nas Figuras 1 e 2 correspondem a um importante produto gerado nessa pesquisa.

Além dessa contribuição científica, o instrumento de pesquisa adotado na etapa de coleta de dados também consiste numa contribuição, pois consolida obras nacionais consagradas e recentes sobre competências e responsabilidades, no âmbito da análise de negócios, servindo para mensurar a presença e a importância do perfil e do papel do Analista de Negócios, tendo em vista os valores do coeficiente Alfa de Cronbach e por não ter sido encontrado outro instrumento já validado em pesquisas anteriores.

Quanto à contribuição gerencial, o trabalho destaca a importância do Analista de Negócios dentro de uma organização, fato que hoje ainda é uma profissão pouco difundida entre as empresas. Um dos desafios da análise de negócios é conseguir que as pessoas nas organizações entendam o que é efetivamente a análise de negócios e que reconheçam o valor do papel do Analista de Negócios para a gestão do negócio e de seus processos.

A partir da definição formal da ocupação de Analista de Negócios pelo MTE espera-se que com o passar dos próximos anos ocorra um amadurecimento dessa profissão no mercado de trabalho e que as organizações aprendam a gerenciar esses profissinais de forma eficiente, para o alcance de seus objetivos.

O tamanho da amostra nesse estudo pode ser explicado pelo fato da profissão de Analista de Negócios ser pouco difundida e estar em amadurecimento, no cenário nacional. Ademais, uma vez que se adota amostra da população, essa pesquisa está limitada e sujeita à incerteza em relação à representatividade dessa amostra. Qualquer generalização, a partir dos dados da amostra dessa pesquisa está sujeita ao erro amostral e poderia ser feita estatisticamente para a população, caso se tratasse de uma amostra probabilística.

No que tange a dar continuidade ao presente trabalho sugere-se uma investigação de como desenvolver nos Analistas de Negócios, as competências identificadas nessa pesquisa, bem como a validação das responsabilidades desse papel, numa determinada organização. Também sugerem-se replicações desse estudo em outros países, para fins de comparação em relação à influência cultural e ao amadurecimento dessa profissão. Além disso, uma proposição de mecanismos ou instrumentos de avaliação do desempenho do Analista de Negócios e um estudo de caso, que analise em termos de desperdício e de baixo retorno dos investimentos, o fato dos requisitos de negócio não serem bem elicitados e entendidos pela equipe de TI ou de SI.

\section{REFERÊNCIAS}

[1] Cooper, D.; Schindler, P. 2003. Método de pesquisa em Administração, $7^{a} e d$. Porto Alegre: Bookman.

[2] Hair, J. F. 2005. Fundamentos de métodos de pesquisa em Administração. Porto Alegre: Bookman.

[3] Hoppen, N. E. 1996. Um guia para a avaliação de artigos de pesquisas em sistemas de informações. Porto Alegre: READ.

[4] Neves, M. 2012. Análise de Negócios para Curiosos, versão 1.0. AN202.
[5] Saviani, J.R. 1998. O Analista de Negócios e da Informação - O Perfil Moderno de um Profissional que Utiliza a Informática para Alavancar os Negócios Empresariais. São Paulo: Atlas.

[6] Thomé, S. 2012. Análise de Negócios 2012+. Interdual. https://www.youtube.com/watch?v=hZN9OOAB3aU.

[7] QUALTRICS. c2014. Qualtrics: Online Survey Software \& Insight Plataform. http://www.qualtrics.com.

[8] Vale, L.; Albuquerque, A.; Beserra, P. 2011. A Importância da Qualidade Profissional dos Analistas de Requisitos para o Sucesso dos Projetos de Desenvolvimento de Software: um Estudo para Identificar as Habilidades Mais Relevantes. In 25th SBES, pp. 253-262, doi 10.1109/SBES.2011.24.

[9] International Institute of Business Analysis (IIBA). 2011. $O$ guia para o corpo de conhecimento de análise de negócios (Guia BABOK®), versão 2.0. IIBA: 2011.

[10] Marques, E. 2010. CBAP ${ }^{\circledR}$ prep: certified business analysis professional, seu guia para o certificado profissional em análise de negócio. São Paulo: All Print Editora.

[11] Porto, J. B. 2013. Análise de competências docentes na educação a distância via Internet. Dissertação (Mestrado em Administração), FACE-PUCRS, Porto Alegre.

[12] Bitencourt, C.; Azevedo, D.; Froehlich, C. 2013. Na trilha das competências: caminhos possíveis no cenário das organizações. Porto Alegre: Bookman.

[13] BEHAR, P. A. (Org.). 2013. Competências em educação a distância. Porto Alegre: Penso.

[14] International Institute of Business Analysis (IIBA), Capítulo São Paulo. 2012. Pesquisa Salarial 2012.

http://www.iiba.org.br/images/lyftenbloggie/pesquisas/pesqu isasalarial2012.pdf

[15] Fitzgerald, M. 2012. Carreira: analista de negócios em TI está em alta nas empresas. Computerworld. http://computerworld.com.br/gestao/2012/07/13/analista-denegocios-em-ti-esta-em-alta-nas-empresas/

[16] Brasil. Ministério do Trabalho e Emprego (MET). c2015. Classificação Brasileira de Ocupações - CBO. Brasília. http://www.mtecbo.gov.br

[17] Araujo, M.H.; Albuquerque, J.P. 2010. Analisando Aspectos Sociais e Organizacionais da Modelagem de Processos de Negócios: Uma Abordagem Sociotécnica. In VI SBSI, Marabá, Pará. http://www.lbd.dcc.ufmg.br/colecoes/sbsi/2010/0025.pdf

[18] Santos, H.M.; Santana, A.F.; Alves, C.F. 2011. Análise de Fatores Críticos de Sucesso da Gestão de Processos de Negócio em Organizações Públicas. In VII SBSI, Bahia. http://www.lbd.dcc.ufmg.br/colecoes/sbsi/2011/analisedefato res.pdf

[19] Santos, H.M. et al. 2014. Identifying Strategies for Managing Critical Success Factors of BPM initiatives in Brazilian Public Organizations. In X SBSI, Londrina, Paraná. http://www.lbd.dcc.ufmg.br/colecoes/sbsi/2014/001.pdf 